Document downloaded from:

http://hdl.handle.net/10251/34802

This paper must be cited as:

García Prats, A.; González Villa, FJ. (2011). Using Location-Allocation Algorithms to Distribute Multioutlet Hydrants in Irrigation Networks Design. Journal of Irrigation and Drainage Engineering. 274-283. doi:10.1061/(ASCE)IR.1943-4774.0000405.

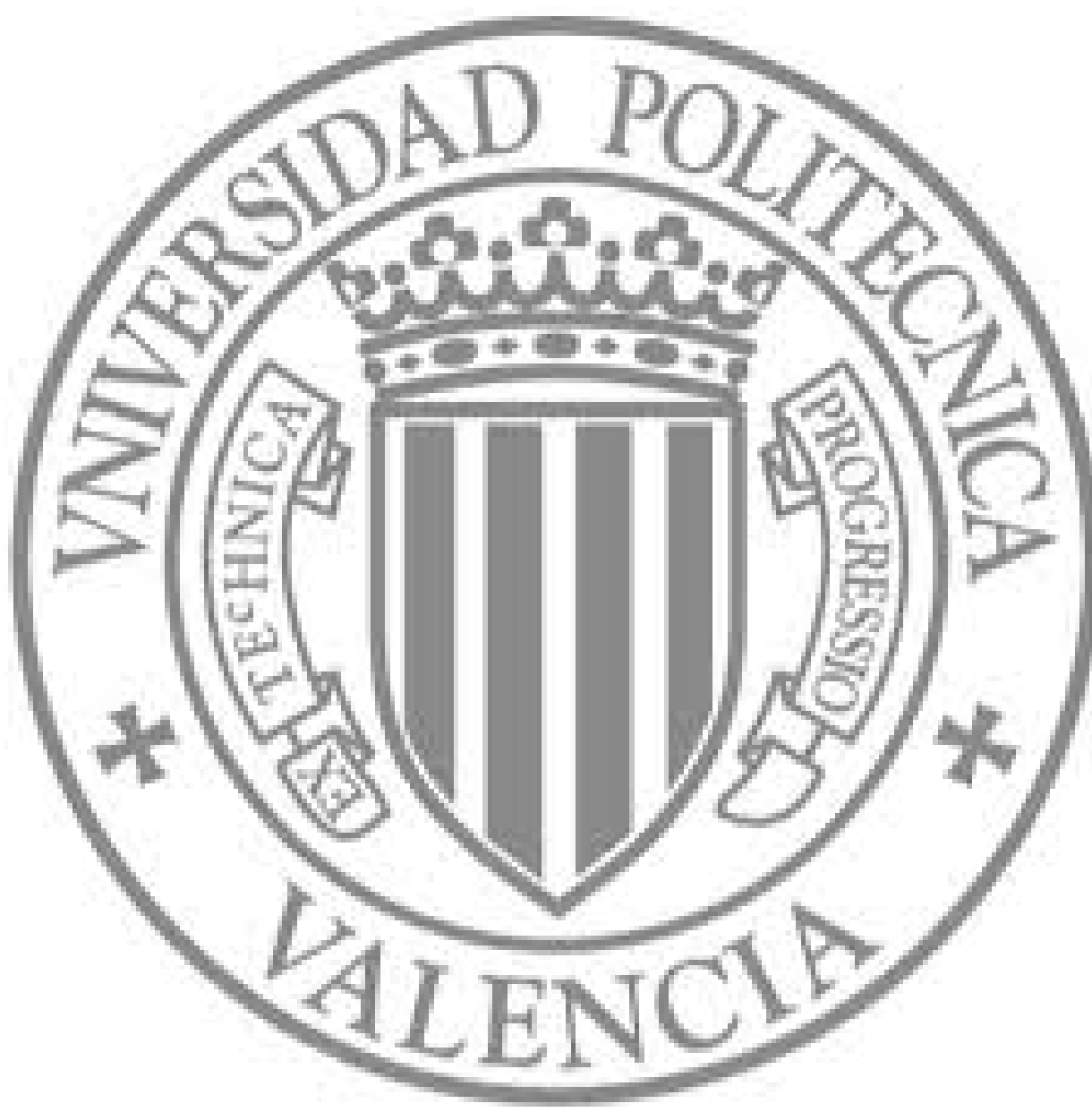

The final publication is available at

http://dx.doi.org/10.1061/(ASCE)IR.1943-4774.0000405

Copyright American Society of Civil Engineers 


\title{
USING LOCATION-ALLOCATION ALGORITHMS TO DISTRIBUTE MULTIOUTLET HYDRANTS IN IRRIGATION NETWORKS DESIGN
}

\author{
Francisco González Villa ; Alberto García Prats²
}

\begin{abstract}
Location-allocation algorithms allow for situating services in an efficient way in zones where the demand is disperse accross the territory. In the present work, the minisum location-allocation algorithm has been used to optimize the situation of the multioutlet hydrants, which needs an irrigable zone to be supplied. The objective function aims at minimizing the total access costs of the service. In this sense, an application case has been solved. The total number of hydrants is the same as the currently existing, in such a way that the results can be compared with the presented solution. The model reduces the total distance run to access the service, from 16,177 $\mathrm{m}$ to 13,560 $\mathrm{m}$ (16.17\%) and also the objective function (proportional to the cost) by $28.95 \%$.
\end{abstract}

CE Database subjetc headings: Multioutlet hydrant; Irrigation network; Locationallocation algorithm; Minisum; Operational research; Geographical information system (GIS).

\section{Introduction}

To approach the design of a pipe-network distribution system for irrigation, certain steps need be taken (Labye et al. 1988). First, the hydrants (delivery points) are distributed around the area to be irrigated by grouping together a number of plots according to their size, approximately between four and six. In the second stage, the hydrants join the supply point through a pipe network. This stage is referred to as the layout design. In the third stage, the flow circulating through the pipes is determined

\footnotetext{
${ }^{1}$ PhD Student. Departamento de Ingeniería Hidráulica y Medio Ambiente. Universidad Politécnica de Valencia. Camino de vera s/n. 46020. (Valencia). España.

${ }^{2}$ Professor. Departamento de Ingeniería Hidráulica y Medio Ambiente, Universidad Politécnica de Valencia, ETSIAMN, Camino de Vera s/n. Valencia, España (corresponding author). 
according to the hypothesis of on-demand supply (Clement 1966) or through a turntaking system (Labye et al. 1988). Finally, every pipeline is sized. This last stage is usually carried out by employing mathematical optimization procedures. The exact position of the hydrants depends on the agreement reached among the consumers, who all wish to be near the hydrants, and the network management company, whose aim is to economize and install only those points that are strictly necessary (Labye et al. 1988). In the last three decades a significant number of methodologies have been developed for solving the last stage only, or the second, third and last stage together, using several mathematic methodologies.

However, very few methodologies have been developed to solve only the second stage (García-Prats and Guillem-Picó 2007, 2009). Despite its importance, not many approach exist in the scientific literature about how to distribute multioutlet hydrants in irrigation networks design.

Location-allocation problems concern the provision of a service to satisfy a spatially dispersed demand. For reasons of cost, service must be provided from a few centralized locations (hydrants). The problem has two elements: where to put the hydrants (location), and which subsets of demand (irrigated plots) should be served by each hydrant (allocation). Location theory was first formally introduced in 1909 by Alfred Weber (1909, 1971), who considered the problem of locating a single warehouse to minimize the total travel distance between the warehouse and a set of spatially distributed customers. Location-allocation problems was first discussed by Miehle (1958) and later accurately formulated by Cooper (1963, 1964, 1967). Today, locationallocation problems are an important part of operational research science.

In this work, the use of a location-allocation algorithm to place or distribute the hydrants in an irrigation network is proposed. The spatial information required is obtained by implementing the studied zone in to a geographical information system. The information is processed using the General Algebraic Modeling System (GAMS) mathematical optimization software. In this study, a real irrigable zone is presented. Hydrants and connecting pipes to current plots are compared with the results obtained in the application of the developed model. 


\section{MATERIALS AND METHODS}

\section{Model description}

Among the different location-allocation models, the selected one for the hydrants situation is the so called minisum. The objective of the model is to assign -to each demand point- the offer point that succeeds in minimizing the total movement costs. In our case, we aim at minimizing the total cost of the required pipes to link every plot with a hydrant. Due to the fact that the cost of a pipe is proportional to both the supplied area and the distance run, we will utilize the product of these two variables as a tool for estimating the cost. The objective function does not define a real cost in itself, but a value directly proportional to it.

The objective function minimizes the sum of distances weighted by the size of plots and is as follows:

$$
\text { Minimize } Z=\sum_{i=1}^{m} \sum_{j=1}^{n} a_{j} \cdot d_{i j} \cdot s_{i j}
$$

where: $Z$ is the value of the objective function $\left(\mathrm{m}^{2} \cdot \mathrm{m}\right.$; proportional to the overall cost of the pipes; units with no physical sense); $a_{j}$ is the area of each irrigated plot $\left(\mathrm{m}^{2}\right) ; d_{i j}$ is the distance (m) from every candidate point (for a hydrant $i$ and a plot $j$ ); and $s_{i j}$ is a binary term called "service", it being 1 when the plot $j$ is served by a hydrant $i$ and 0 in the opposite case. The total number of plots is $n$, whereas the total number of candidate points where hydrants can be located is $m$. Taking into account that the latter is far higher than the number of hydrants, another binary variable $h_{i}$ should be defined, in such a way that $h_{i}$ equals 1 when a location contains a hydrant, and 0 in the opposite case.

The model is subjected to the following restrictions that allow for delimiting the feasible region:

$$
\begin{gathered}
\sum_{i=1}^{m} s_{i j}=1, \forall j=1, \ldots, n \\
\sum_{i=1}^{m} h_{i}=H N
\end{gathered}
$$




$$
\begin{aligned}
& l_{b} \cdot h_{i} \leq \sum_{j=1}^{n} s_{i j}, \forall i=1, \ldots, m \\
& \sum_{j=1}^{n} s_{i j} \leq u_{b} \cdot h_{i}, \forall i=1, \ldots, m
\end{aligned}
$$

Where $l_{b}$ and $u_{b}$ are the lower limit (minimum number) and upper limit (maximum number) of plots respectively, that can be assigned to the same hydrant; $\mathrm{NH}$ is the total number of hydrants to be located.

The feasible region contains all possible values that decision variables may take. A given plot can never be supplied by more than a hydrant. Therefore, only one service can be assigned from a hydrant to a plot (eq. 2).

The total number of hydrants that will supply the plots should be a fixed number, $\mathrm{NH}$, known in advance (eq. 3).

To prevent some hydrants from remaining unlocated (no plots assigned) and others with a great deal of plots, both lower and upper limits of supplied plots by the same hydrant are set (eq. 4 and 5).

The initial data to solve the problem are the total number of plots $n$, their respective areas $a_{j}$, the total number of hydrants $N H$, the total number of candidate points where a hydrant $m$ can be located, and the distances between these candidate points and each plot $d_{i j}$. The resulting mathematical model is the type of binary integer programming (BIP). The decisión variables are $s_{i j} \mathrm{y} h_{i}$, which can only take the values 0 or 1 since they are binary-type variables.

The GAMS (General Algebraic Modeling System) optimization software (Brooke et al., 1992) has been used to solve the optimization model. The solver chosen in this case has been Cplex version 10.1.1, which easily adapts itself to the BIP models.

\section{Getting distances}


Within the initial information required to solve the problem we can find the distance between candidate points (for placing hydrants) and plots. This distance can be measured following different procedures, Figure 1 showing the two most frequent methods: Euclidean distances (ED) and distances through the plot network (DTNP).

The euclidean distance is the straight line distance between two points. The first point is the hydrant, whereas the second one is the plot centroid. It can be easily obtained, with low computation costs, although it scarcely resembles the reality, since supply pipes never cross through the parcels (they run along the plot boundaries instead). The final result is an $m x n$ distance matrix (with $m$ candidate to hydrant points and $n$ plots).

Distances through the plot network are rather difficult to calculate, but they in turn provide a high precisión since they exactly fit the reality. In this case network means the set of plot boundaries and the nodes formed in the confluence of two or more boundaries. The starting point is the hydrant and the arrival is the closest vertex to the supplied plot. Figure 2 shows the irrigable zone decomposed as a network so as to be able to utilize it in the calculation of distances.

Both alternatives are studied using a geographic information system (GIS).

The distance across the plot network requires the obtainment of the shortest path between the origin and the target. This is the popular problem of the "shortest path" in graph theory. The difference consists of the fact that in the former case we have one origin but several targets. For each plot we are interested in the distance between the candidate point to become a hydrant and the closest vertex to all of them. For this reason the problem is solved in two stages:

- Firstly, we obtain the shortest path between each candidate point to be a hydrant and all the vertices of each plot. Shortest paths are obtained with the Dikjstra's algorithm (Dijkstra, 1969) implemented in Matlab. The result is an array with the minimum distances between all vertices. The sequence of boundaries forming each path is also obtained. 
- Afterwards, for each plot and for each candidate to hydrant point, the minimum route is selected. Thus, we again obtain an $m \times n$ matrix, with $m$ candidate to hydrant points and $n$ plots.

\section{Case study}

The studied case corresponds to an irrigable zone with a total area of 202 ha. The number of plots is $n=374$. The average area per plot is 0.54 ha. Irrigation zones have a pressurized branched irrigation network organized to work on-demand supply. Figure 3 shows the present distribution of the plots and the hydrants that supply them.

The candidate points for hydrants are all the vertices formed by the confluence of two or more plot limits. In the studied zone we have obtained $m=659$ candidate points of $n=$ 374 plots.

In order to compare the result of the model with the present situation, the number of hydrants to be located is the same as the currently existing: $N H=47$.

The lower and upper limits of the plots assigned to the same hydrant are set at $l_{b}=6$ and $u_{b}=10$.

The use of a geographical information system (GIS) allows for obtaining the lengths of each plot boundary, the connectivity matrix between vertices and boundaries, as well as the area of each plot. The ED distance matrix can also be obtained through the utilization of GIS. The DTNP distance matrix is obtained from the connectivity matrix and the length of the boundaries, employing MATLAB.

Pipes linking the hydrants with the existing plots have been carried out following the Plot limits (distances across the plot network). Hydrants are then linked with the nearest point of the supplied Plot. The results of the application of the model (using both ED distances and DTNP distances) will be compared with the currently installed pipes (CIP). 


\section{RESULTS AND DISCUSSION}

After the optimization process, the result obtained for each case is a matrix of distances between each one of the selected NH vertices (where the hydrants will be located) and the supplied plots. The vertices selected as hydrants are those that minimize the total cost of plot access to the service (irrigation water) concentrated on the hydrants. The model is solved for ED distances as well as for DTNP distances. ED distances (shown in Figure 4) are only used to solve the location-allocation model. After knowing the vertices containing the hydrants and the plots assigned to each hydrant, we calculate the distances to be run between each hydrant and their plots through the Plot network; otherwise the results would not be comparable, since a hydrant-plot pipe is never built crossing other plots and arriving at the centroid. This may be clearly noticed in the detail of Figure 4.

The resulting distance matrices are implemented in the GIS. Figures 4 and 5 show -for each type of plot employed- the vertices selected as hydrants and the plots assigned to each hydrant.

The cost of the pipe linking a hydrant and a plot is a function of the supplied plot and the distance. In order to simplify the model, we have decided to use the product between areas and distances $\left(\mathrm{m}^{2} \cdot \mathrm{m}\right.$ ) (instead of a more complex function related to the diameter calculation). The optimization model minimizes the value of the objective function.

This objective function gets a value of 99,103,243 $\mathrm{m}^{2} \cdot \mathrm{m}$ for ED distances and $43,048,586$ in case of DTNP distances. CIP pipes result in a value of 60,596,559. All these data are summarized in Table 1 . If we simply take into account the total distance required for linking all plots with some hydrant, the corresponding values are 25,238 m for ED, 13,560 $\mathrm{m}$ for DTNP, and 16,177 $\mathrm{m}$ for CIP. Therefore the application of the optimization model with DTNP allows for a $28.95 \%$ reduction in the value of the objective function (proporcional to the real cost), and a 16,18 \% decrease in the total pipe length, when compared to CIP . The model makes the existing actual situation get worse when ED is employed. The value of the objective function increases by $63.54 \%$, whilst the increase in the required pipe length is $56.01 \%$. Mean value and standard deviation have been calculated from both the value of the objective function and the 
distance among plots and hydrants. We may notice that a lower dispersion exists when distances measured through the plot network are used, and therefore the average value of lengths among hydrants and plots is not only lower but it has less uncertainty.

When the result shown in Figures 4 and 5 is analyzed, it may seem that the application of the location-allocation model yields similar results for both types of distances used. However, we have seen that from a numerical point of view they are completely different. The DTNP makes CIP improve, whereas ED notably worsens it. This can be attributed to the meaning of the word "near" for each of the distance types. As shown in the detail of Figure 3, a plot that remains close to a hydrant following a straight line may stay far away through the plot network, since it requires to surround others. In the optimization process, those locations that are affected by the last fact are being rejected when the distances are measured through the plot network.

Another important aspect to be remarked in the performance of the model is the one deriving from the structure of the objective function. This objective function is the product between an area and a distance, which is proportional to the cost of the pipe. In the DTNP case, a hydrant located in a plot vertex does not cause an increase in the objective function, since the distance to be run for reaching it is zero. This means that, in the optimization process, the plots with the highest areas have a hydrant in their perimeter. Nevertheless, in case of ED, the plots we may see near the hydrant (following a straight line) through the plot network often result in a certain distance which, no matter how small it may be, makes the objective function increase.

Another way of observing this effect is presented in Figure 6. It shows the average plot length required to link a plot with its hydrant, plot areas being segmented in ranges. The success of the DTNP case (Figure 6A) is due to the fact that the model aims at locating hydrants in touch with the biggest plots, in such a way that the objective function does not increase. With respect to ED case (Figure 6B), plots that were seemingly near were really far away through the network, which means that we have lengths over $50 \mathrm{~m}$ in nearly all area ranges. Finally, in Figure 6C we can notice how the network designer, by defining CIP, has followed a similar criterion to that shown in Figure 6A. He has placed the hydrants in contact with the biggest plots, so that the farthest plots are the smallest and consequently their pipes connecting the hydrant will have the lowest cost. 
Obviously, and although the philosophy is the same, the fact of carrying out the process manually does not permit to be as rigorous as the optimization model; thus the results obtained are worse.

Another way of analyzing the behavior of the model according to the distance employed is shown in Figure 7; the number of cases and the percentage of total area in each length range have been represented. With respect to DTNP, and using zero meters of pipe length (plots having a hydrant in a vertex of its perimeter), more than $80 \%$ of the area was assigned to a hydrant, whereas in case of ED the figure scarcely reached $70 \%$. As far as CIP is concerned, the corresponding percentage was also close to $80 \%$.

As regards the maximum length assigned, the DTNP method is $295 \mathrm{~m}, 692 \mathrm{~m}$ being for ED and $228 \mathrm{~m}$ for CIP. In this case, DTNP exceeds the maximum length between a hydrant and an assigned plot, because no restriction has (deliberately) been imposed in this sense on the optimization model so as to observe its behavior.

\section{CONCLUSIONS}

In pressurized Irrigation systems with multiuser hydrants the service remains somewhat far away from the plot where it is used. The literature scarcely reports any case describing how the hydrants should be placed within the irrigation network. The cost of pipes among hydrants and plots depends on both the hydrants location and the plots assigned to each one of them. Location-allocation algorithms help to find solutions that minimize the aforementioned cost. In this work, the minisum algorithm has been utilized to carry out this task, and two ways of measuring distances have been employed and later compared with the currently existing pipes.

The application of this technique requires the use of geographical information systems (GIS) for spatial information management, as well as mathematical programming software to solve the optimization model raised. 
The utilization of distances through the plot network is indispensable, since the employment of euclidean distances causes the loss of a great amount of information and unsuitable solutions are generated.

An important parameter in the model is the number of hydrants to be allocated. It influences on the average number of plots per hydrant and also on the pipe length required to link all the plots to any hydrant. In this case, the number of hydrants (NH) used is the same as the one actually existing, so that solutions can be compared. Future works will study the effect of increasing or decreasing $\mathrm{NH}$, taking into account the high cost of these structures. This would permit to obtain -in a single process- the optimum number of hydrants that minimize the total cost due to the hydrants themselves plus the linking pipes with the parcels.

\section{ACKNOWLEDGMENTS}

The writers like to thank Vicent Giner Bosch or his collaboration in the model development. 


\section{FIGURES}

Figure 1. Euclidian distances (a) and distances across the plot network (b).

Figure 2. Network formed by the plot limits. The confluence of two or more limits forms the vertices.

Figure 3. Present location of hydrants in the studied area and assigned plots.

Figure 4. Location of hydrants and allocated plots, for euclidean distances.

Figure 5. Location of hydrants, assigned plots, and pipes, for distances measured through the plot network.

Figure 6. Average length for different plot sizes

Figure 7. Percentage of total area and number of cases in each length range 


\section{TABLES}

Table 1. Total, mean, and dispersión value of the objective function and the total pipe length required to link hydrants and assigned plots. 


\section{NOTATION}

$Z$ = value of the objective function $\left(\mathrm{m}^{2} \cdot \mathrm{m}\right.$; proportional to the overall cost of the pipes; units with no physical sense).

$a_{j}=$ area of each irrigated plot $\left(\mathrm{m}^{2}\right)$.

$d_{i j}=$ distance from every candidate point (for a hydrant $i$ and a plot $j$ ) (m).

$s_{i j}=$ binary term called "service", it being 1 when the plot $j$ is served by a hydrant $i$ and 0 in the opposite case.

$n=$ total number of plots.

$m=$ total number of candidate points where hydrants can be located is.

$h_{i}=$ binary variable in such a way that $h_{i}$ equals 1 when a location contains a hydrant, and 0 in the opposite case.

$l_{b}$ and $u_{b}=$ lower limit (minimum number) and upper limit (maximum number) of plots respectively, that can be assigned to the same hydrant.

$\mathrm{NH}=$ total number of hydrants to be located. 


\section{REFERENCES}

Brooke, A. ; Kendrick, D. and Meeraus, A. (1992). « GAMS: A User’s Guide ». The Scientific Press. Redwood City. California.

Clement, R. (1966). “Calcul des debits dans les reseaux d'irrigation fonctionant a la demande.“ Le Huille Blanch, Vol.Nº 5, 553-575. (in French)

Cooper, L. (1963). “Location-allocation problems”. Operations Research. 11(3), 331-343.

Cooper, L.(1964). “Heuristics methods for location-allocation problems”. Society for Industrial and Applied Mathematics Review. 6, 37-53.

Cooper, L. (1967). “Solutions of generalized location equilibrium models”. Journal of Regional Science. 7(1), 1-18.

Dijkstra, E.W. (1959). “A note on two problems in connection with graphs.” Numerische Math.,. Vol.1, 269-271.

García Prats, A. and Guillem Picó, S. (2007). “Layout Design of Irrigation Networks in Highly Parcelled Territories Using Geographical Information System”. Journal of Irrigation and Drainage Engineering. ASCE, 133(6), 573-582.

García Prats, A. and Guillem Picó, S. (2009). "Influence of the spatial configuration of the irrigated zone on the irrigation network layout design”. Journal of Irrigation and Drainage Engineering. ASCE, 135(5), 626-632.

Labye, Y.; Olson, M.A.; Galand, A. y Tsiourtis, N. (1.988). "Design and optimization of irrigation distributions networks.” Irrigation and Drainage $n^{\circ}$ 44. FAO. Roma. 
Miehle, W. (1958). “Link-length in netwoks”. Operations Research. 6(2), 232-243.

Weber, Alfred (1909). “Über den Standort der Industrien, Erster Teil: Reine Theorie des Standortes”. Tübingen: Mohr. (in Germany).

Weber, A. (1929).” Theory of The Location of Industries” (translated by C.J. FREIDRICH, 1929). Chicago : University of Chicago Press. 
Table 1. Total, mean, and dispersión value of the objective function and the total pipe length required to link hydrants and assigned plots.

\begin{tabular}{lcc|cc|cc}
\hline & \multicolumn{2}{c|}{ Total } & \multicolumn{2}{c|}{ Mean } & \multicolumn{2}{c}{ STDV } \\
\cline { 2 - 7 } $\begin{array}{l}\text { Distance } \\
\text { Type }\end{array}$ & $\begin{array}{c}\text { O. F. Value } \\
\left(\mathrm{m}^{2} \times \mathrm{m}\right)\end{array}$ & $\begin{array}{c}\text { Length } \\
(\mathrm{m})\end{array}$ & $\begin{array}{c}\text { O. F. Value } \\
\left(\mathrm{m}^{2} \times \mathrm{m}\right)\end{array}$ & $\begin{array}{c}\text { Length } \\
(\mathrm{m})\end{array}$ & $\begin{array}{c}\text { O. F. Value } \\
\left(\mathrm{m}^{2} \times \mathrm{m}\right)\end{array}$ & $\begin{array}{c}\text { Length } \\
(\mathrm{m})\end{array}$ \\
\hline DTNP & $43,048,586$ & 13,560 & 115,103 & 36 & 155,744 & 46 \\
ED & $99,103,243$ & 25,238 & 264,982 & 67 & 439,368 & 86 \\
CIP & $60,596,559$ & 16,177 & 162,023 & 43 & 225,715 & 48 \\
\hline
\end{tabular}


$\sqrt{1=}$

$=$

$1=$ 

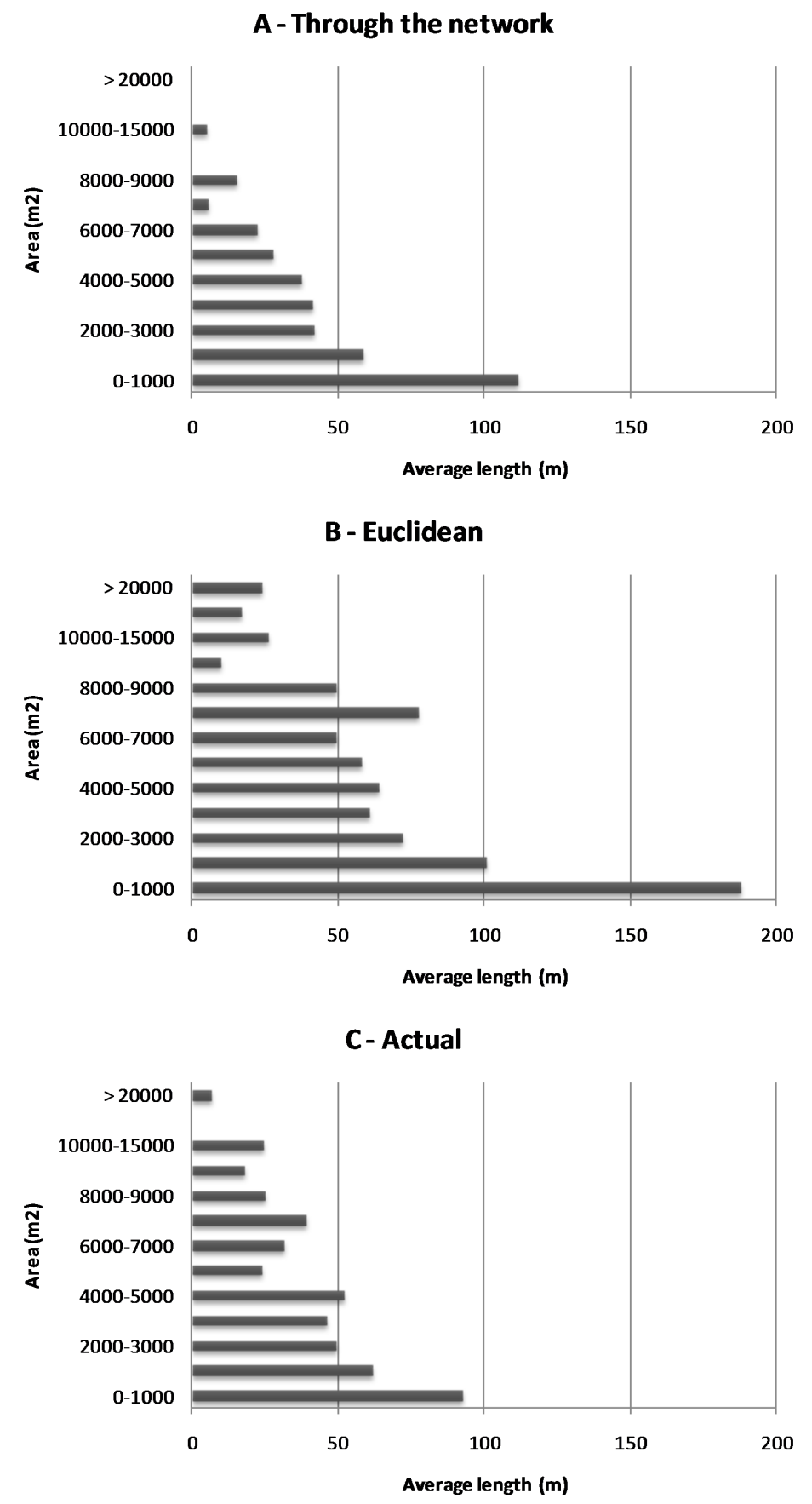


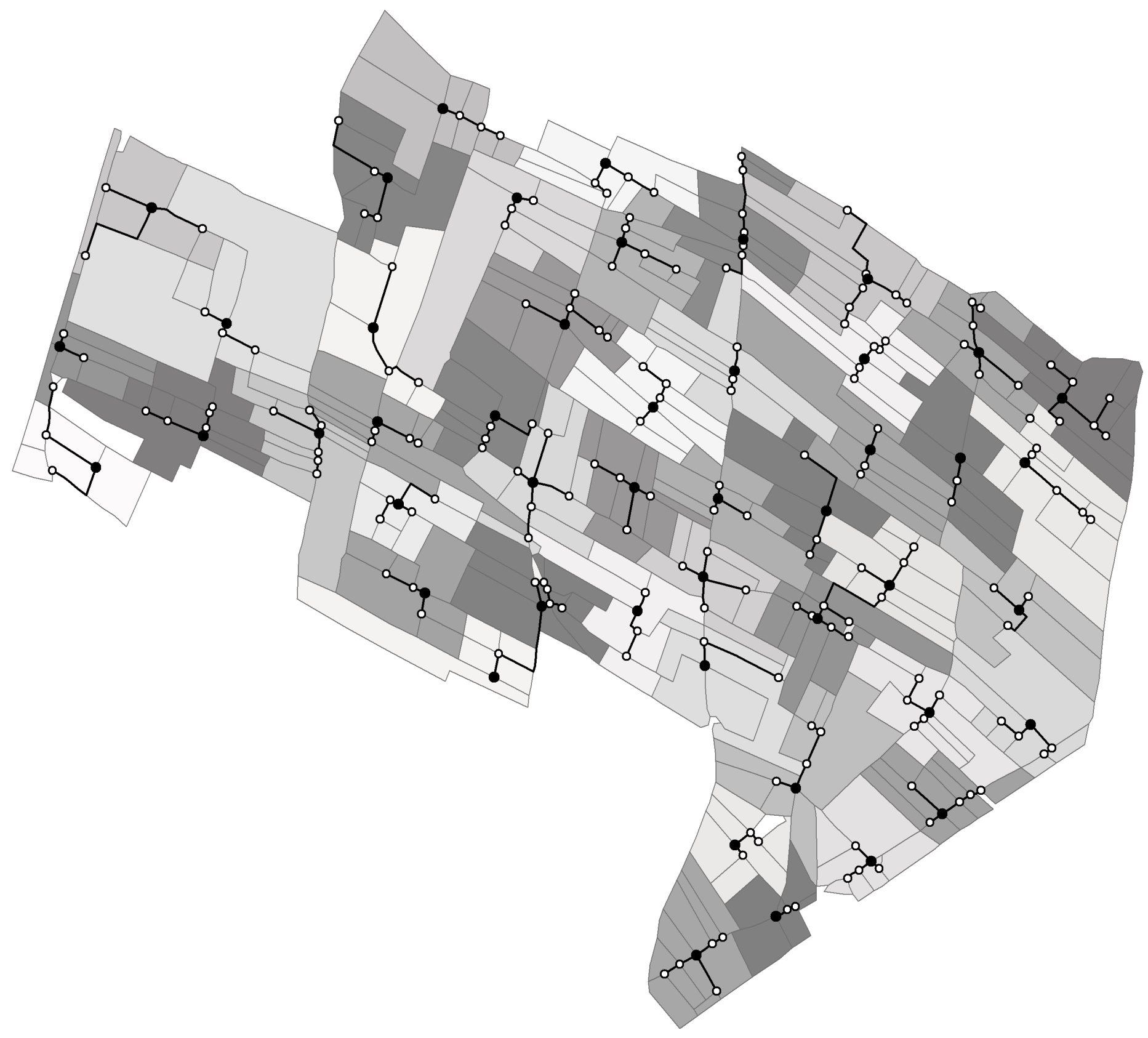




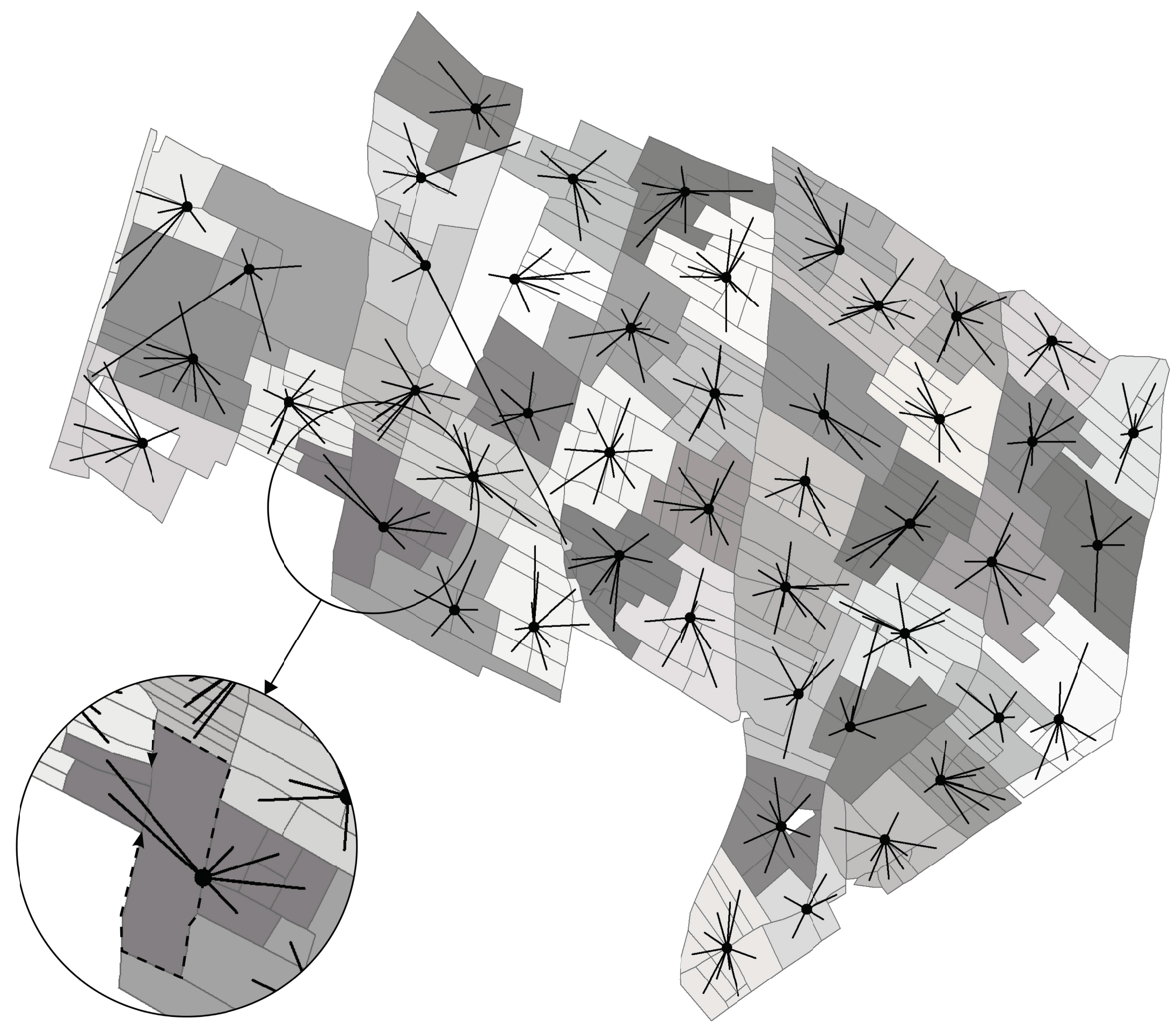




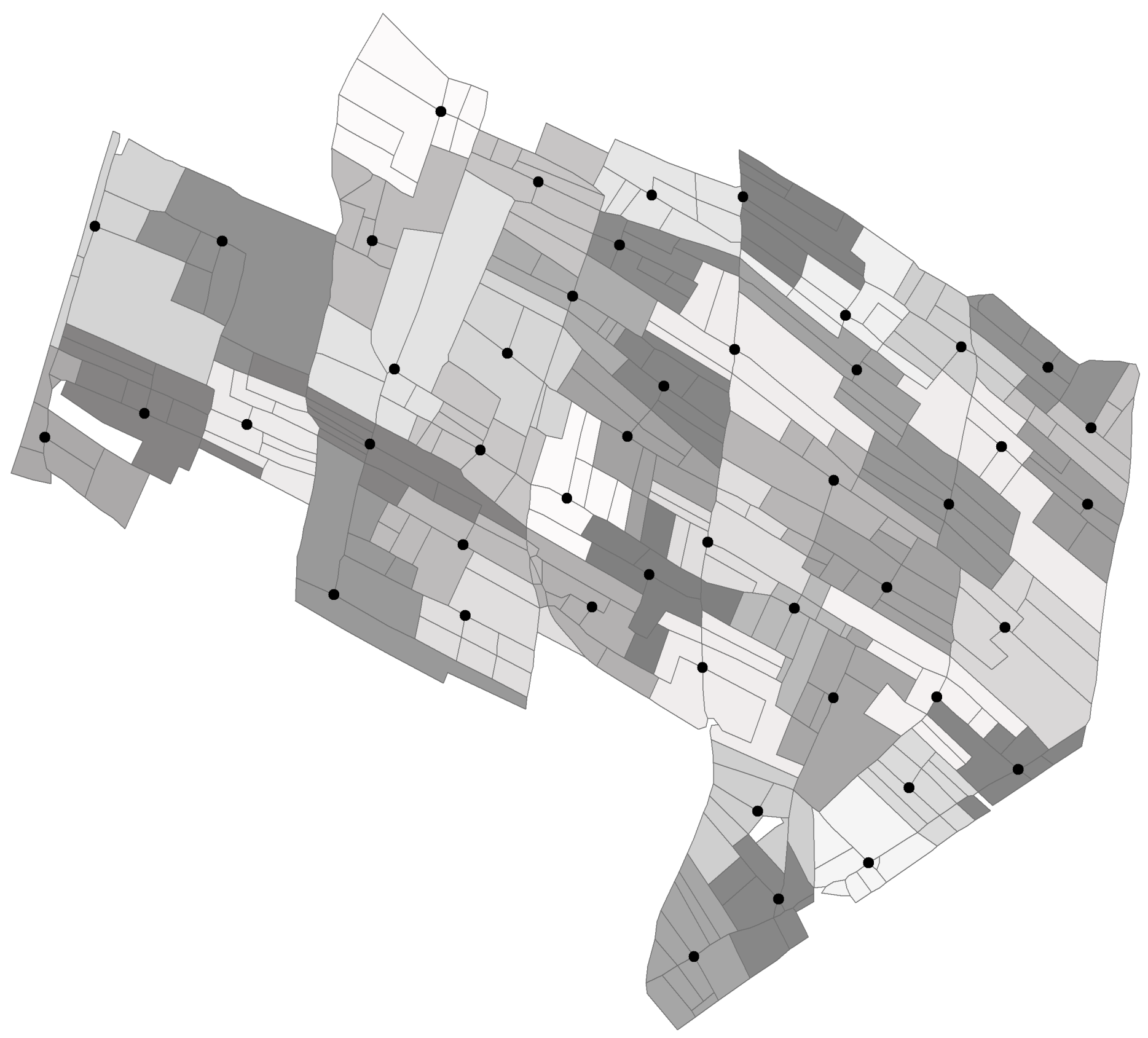




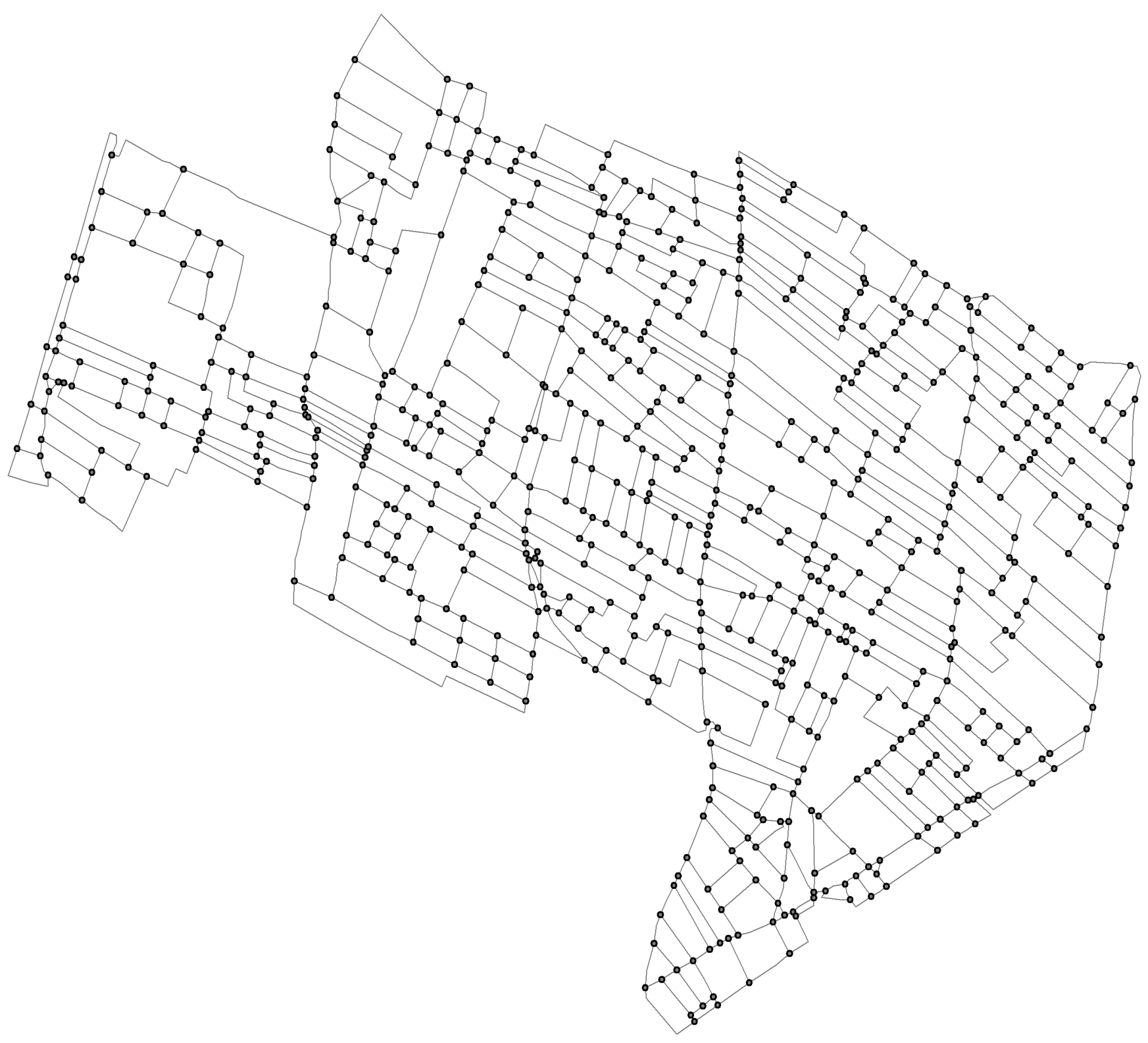




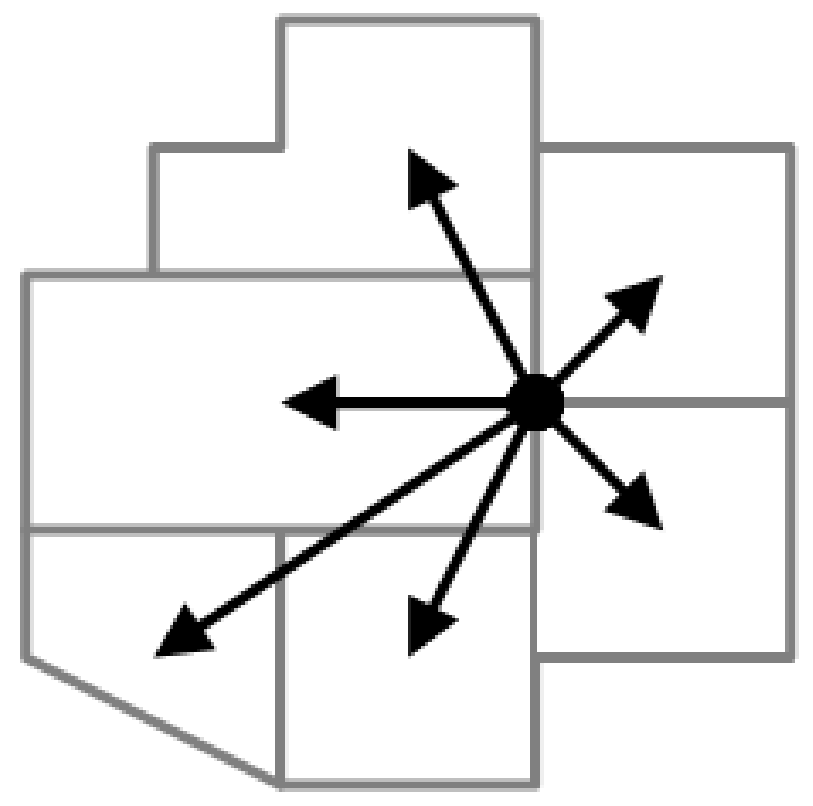

(a)

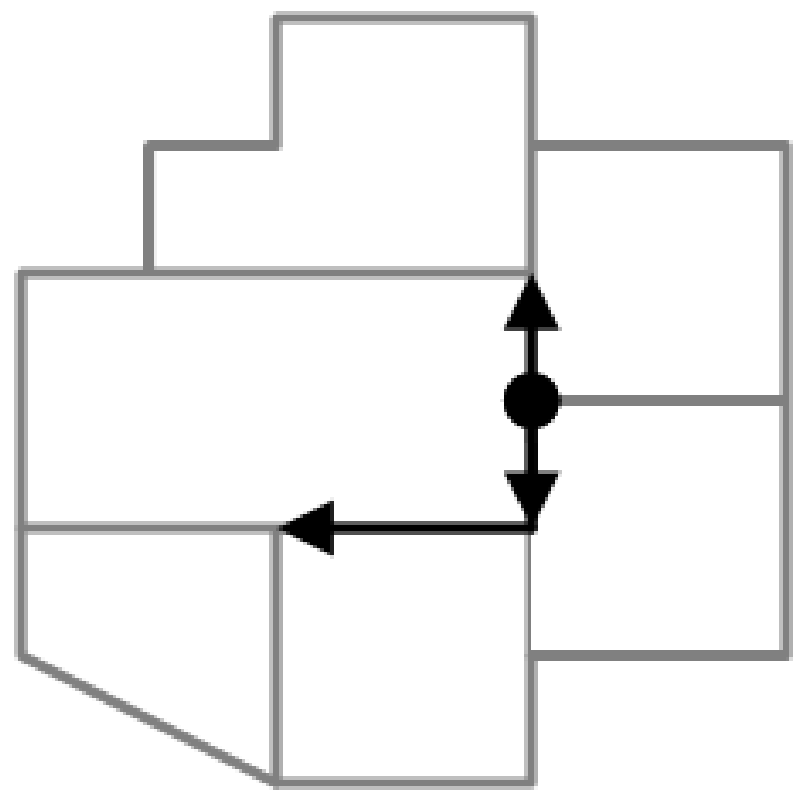

(b) 